\title{
Contamination as the Cause of Erroneous Records of Brochosomes
}

\author{
Roman Rakitov \\ Paleontological Institute, Russian Academy of Sciences, Profsoyuznaya Street 123, Moscow 117997, Russia \\ Correspondence should be addressed to Roman Rakitov, rakitov@gmail.com
}

Received 27 March 2011; Accepted 9 April 2011

Academic Editor: Ai-Ping Liang

Copyright ( $) 2011$ Roman Rakitov. This is an open access article distributed under the Creative Commons Attribution License, which permits unrestricted use, distribution, and reproduction in any medium, provided the original work is properly cited.

Brochosomes are ultramicroscopic particles produced in large quantities by the Malpighian tubules of leafhoppers (Insecta, Hemiptera, and Cicadellidae) and applied by leafhoppers as a coat to their integuments. A recent study has described brochosomes on museum specimens of Heteroptera and Psylloidea, suggesting a wider distribution of brochosomes among Hemiptera. Here, I report that the majority of adult Sthenarus rotermundi (Scholtz) (Miridae) and Kleidocerys resedae (Panzer) (Lygaeidae) reared in captivity and handled with clean tools had no brochosomes on them, suggesting that the earlier records of brochosomes in these and perhaps other species outside of the Cicadellidae were due to contamination. Additionally, simple experiments demonstrated that insects can become contaminated with brochosomes via entomological tools that had been in contact with leafhoppers and via preservation in ethanol together with leafhoppers. Contamination of host plants, predators, and parasites of leafhoppers with brochosomes is also expected but remains to be demonstrated.

\section{Introduction}

Brochosomes are ultramicroscopic proteinaceous secretory particles, usually $0.3-0.7 \mu \mathrm{m}$ in diameter, with a characteristic honeycombed surface, that have been originally discovered under an electron microscope on the integuments of leafhoppers, true bugs, mosquitoes, flies, sawflies, and chalcidoid wasps [1-3]. Later, Day and Briggs [4] discovered that brochosomes were produced in vast quantities by specialized glandular segments of the Mapighian tubules of leafhoppers (Cicadellidae) and suggested that the earlier records from other insect taxa had been due to contamination. After molts, adult and often also immature leafhoppers release brochosome-containing liquid secretion through their hindguts and actively distribute these particles over their integuments as a nearly continuous hydrophobic coat, which is thought to protect leafhoppers from getting trapped into their liquid excrement [5]. The distribution process is facilitated by specialized rows and groups of leg macrosetae, which coincidentally serve as important diagnostic characters of the Cicadellidae, suggesting that the evolution of this hemipteran family was intimately associated with brochosomes $[6,7]$. After the study by Day and Briggs [4], the idea that brochosome production is unique to Cicadellidae remained unchallenged for a long time, except for a brief report of brochosomes found under SEM on the legs of Cercopoidea [8]. However, a recent well-illustrated study by Wyniger et al. [9] has reported brochosomes on museum specimens of 16 species from 7 heteropteran families (Berytidae, Lygaeidae, Miridae, Plataspidae, Rhopalidae, Saldidae, and Tingidae) and one species of Psylloidea. The authors suggest that brochosomes are in fact widely distributed among Hemiptera, although in the non-cicadellid lineages they are typically produced in much smaller quantities. This view challenges not only the idea of brochosomes as one of the key innovations in the evolution of Cicadellidae, but also their hypothetical primary function as a protective biomaterial. The authors admitted that their observations required fur ther confirmation, because neither the production of brochosomes in the Malpighian tubules or other organs, nor any associated behaviors for their transport onto the integuments had been documented for Heteroptera or Psylloidea. Their data [9] derive credibility primarily from two sources: brochosomes have been found in at least two individuals of each reported species and on many specimens brochosomes occurred in large numbers (most often on the 
legs). It appears, however, that the authors included only positive records: no individuals without brochosomes are mentioned, and the total number of individuals examined for each species is not indicated. Moreover, the observations have been made during a survey of dry museum-preserved specimens collected by various collectors, possibly with different techniques, and clearly not with the purpose of documenting the taxonomic distribution of brochosomes. Another recent report of brochosomes, in a species of Miridae [10], has the same flaw. Similarly, Frost et al. [8] provided no details on their collecting and handling methods, suggesting that no special precautions were observed to avoid possible contamination of their cercopoid specimens. Hypothetically, contamination with brochosomes may occur as a result of collecting and handling cicadellids and other insects using the same equipment (aspirators, killing jars, sweep nets, and forceps) or preserving cicadellids in ethanol together with other insects. Additionally, predators and parasitoids of cicadellids may become contaminated with brochosomes via natural contacts.

In the present study, we examined adults of two heteropteran species listed by Wyniger et al. [9] as bearing brochosomes, Sthenarus rotermundi (Scholtz) (Miridae), and Kleidocerys resedae (Panzer) (Lygaeidae). Among these, $S$. rotermundi has previously been described as displaying the largest amounts of brochosomes among the examined heteropteran species [9]. We used adults reared in the laboratory from immature stages and handled with precautions to avoid contact with leafhoppers or leafhopper-contaminated surfaces. Additionally, we tested whether brochosomes can contaminate insects via shared entomological equipment (an aspirator) and via ethanol.

\section{Materials and Methods}

Nymphs of $S$. rotermundi were collected from white poplars in the city of Moscow, Russia, and reared on cut poplar shoots inside clean $50 \mathrm{~mL}$ Corning tubes. Twenty adults were killed two weeks after the final moult and examined under SEM. Because in the previously studied heteropterans, the largest amounts of brochosomes have been found on the legs [9], the legs were chosen to search for brochosomes. For each individual, one posterior tarsus, tibia, and femur and one anterior tarsus, tibia, and femur were examined at random points at the 10,000x magnification. Five to 26 (average, 11) photographs per individual were taken for documentation.

Nymphs of K. resedae were collected from birch in Kiel, Germany, and reared on cut birch catkins inside plastic Petri dishes. Fifteen adults were killed two weeks after the final moult and examined under SEM. Because in this species, Wyniger et al. [9] had found brochosomes on both the legs and corium, one forewing and one posterior tarsus from each individual were screened at the 10,000x magnification. Photographs were taken for documentation at three random points for each body part.

To test whether insects get contaminated with brochosomes when preserved in ethanol together with leafhoppers, 27 Drosophila melanogaster Meigen fruit flies from a lab culture and five Igutettix oculatus (Lindberg) adult leafhoppers
TABLE 1: Distribution of the total number of brochosomes observed per individual among adults of two heteropteran species reared in captivity.

\begin{tabular}{llccc}
\hline & \multicolumn{4}{l}{$\begin{array}{l}\text { No. of individuals in which the } \\
\text { total number of observed } \\
\text { brochosomes was }\end{array}$} \\
& 0 & $1-10$ & $11-20$ & $>20$ \\
\hline S. rotermundi $(n=20)$ & 14 & 4 & 2 & 0 \\
K. resedae $(n=15)$ & 13 & 2 & 0 & 0 \\
\hline
\end{tabular}

were kept together in $70 \%$ ethanol within a closed $2 \mathrm{~mL}$ plastic microcentrifuge tube for two weeks. Five flies were later pulled out and examined under SEM.

To simulate contamination via entomological equipment, we placed three D. melanogaster for three minutes within an empty $50 \mathrm{~mL}$ plastic Corning tube previously used for aspirating a large number of live Alebra sp. leafhoppers. The flies were subsequently examined under SEM.

All specimens were sputtered with gold and examined under a Vega 3 Tescan scanning electron microscope.

\section{Results}

On 14 out of $20 \mathrm{~S}$. rotermundi and 13 out of $15 \mathrm{~K}$. resedae individuals, no brochosomes were observed (Table 1). The total of one to two brochosomes per individual were recorded in two $K$. resedae and three $S$. rotermundi individuals. In the remaining three $S$. rotermundi, the total of 7,14 , and 18 brochosomes were found. The largest concentration of brochosomes observed was 12 particles in a $8 \times 11 \mu \mathrm{m}$ field of view (Figure 1(a)). The entire set of 310 micrographs of the two species is available from the author upon request.

Both the D. melanogaster flies stored in ethanol together with leafhoppers and those kept in the leafhoppercontaminated aspirator carried individual brochosomes or their groups on various body parts (Figures $1(\mathrm{~b})-1(\mathrm{~d})$ ).

\section{Discussion}

My observations on the two heteropteran species reared in captivity are in stark contrast with the results reported by Wyniger et al. [9]. The majority of individuals had no brochosomes on the examined body parts, and the minority had only a few brochosomes. The discrepancy is particularly striking in the case of S. rotermundi, characterized [9] as the species showing the highest abundance of brochosomes within the investigated Heteroptera and always displaying high number of brochosomes on various body parts, including the tibiae and tarsal segments. The only explanation consistent with the idea of brochosomes being natural secretory products of Heteroptera [9] would be that the experimental insects did not have enough time to accumulate larger amounts of brochosomes on their integuments during the two weeks after the final moult. Such an explanation is highly unlikely. For comparison, Cicadellidae coat themselves with brochosomes within hours after the final molt, before they commence feeding [11]. It is much more likely 


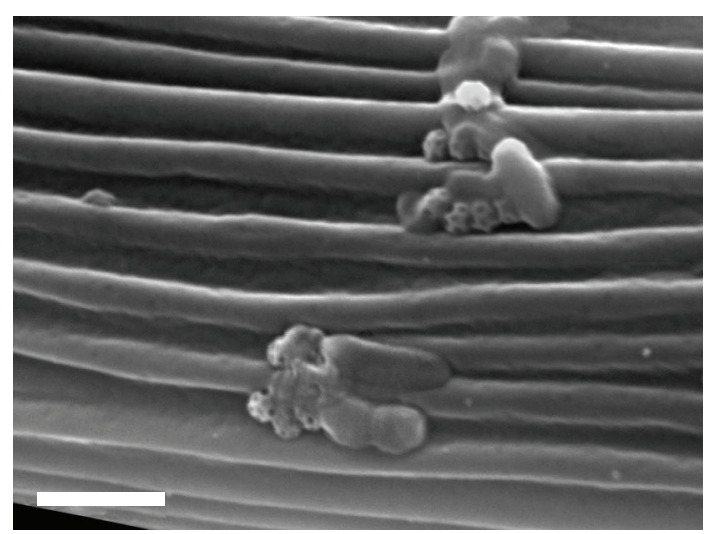

(a)

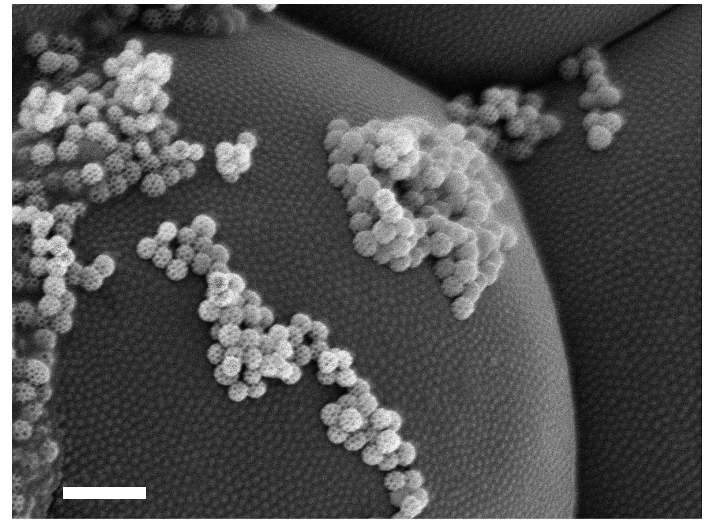

(c)

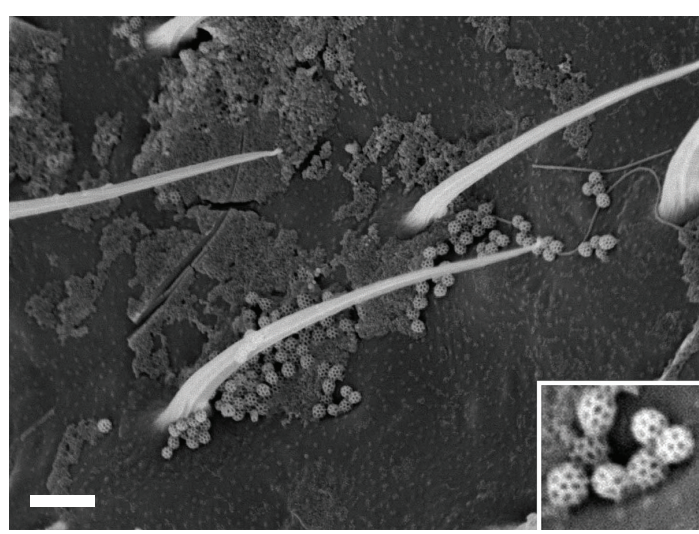

(b)

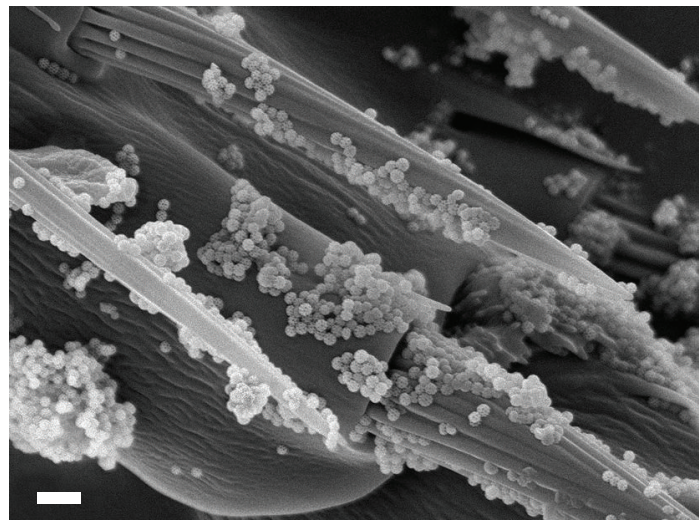

(d)

FIGURE 1: Insect integuments contaminated with brochosomes. (a) Pulvillus of Sthenarus rotermundi reared in captivity, showing the largest concentration of brochosomes (12 particles) observed among heteropteran specimens in this study and some bacteria. (b) Wing of Drosophila melanogaster kept in ethanol together with leafhoppers; inset: close-up of brochosomes. (c) Eye of D. melanogaster kept within a leafhopper-contaminated aspirator reservoir. (d) Tarsus of D. melanogaster kept within a leafhopper-contaminated aspirator reservoir. Scale bars: $2 \mu \mathrm{m}(\mathrm{a}-\mathrm{d})$.

that the few brochosomes observed in this study were due to a failure to completely prevent contamination. Although direct contact with leafhoppers was precluded, the insects molted in captivity had been in contact with cuttings of host plants growing in the wild, which potentially may have been contaminated by leafhoppers. Remarkably, the specimens that displayed the largest number of brochosomes were also visibly contaminated with other extraneous particles, including bacteria (Figure 1(a)).

Therefore, the earlier SEM-based records of brochosomes in Cercopoidea [8], Heteroptera [9, 10], and Psylloidea [9] are most likely explained by contamination. The ultrastructure of the Malpighian tubules has not been adequately studied in Heteroptera, while in Psylloidea these organs are either completely reduced or, possibly, transformed into the so-called midgut appendages [12], which have not been studied using electron microscopy. In contrast, the Malpighian tubules of Cercopoidea have been studied at the ultrastructural level in both immatures [13-17] and adults [18] but are not known to produce brochosomes. It is worth noting that all these hemipterans, but particularly cercopoids, are often collected by the same collectors who collect cicadellids, which increases the probability of contamination.

Among multiple potential routes of such contamination, this study has tested and verified the two most obvious ones: via dry surfaces which had been in contact with leafhoppers and via ethanol. The outer integument of most leafhoppers is completely coated with a sheath of brochosomes [5]. These ultramicroscopic particles easily come loose at contact and adhere to foreign surfaces. As a result, sweepnets, aspirators, killing jars, forceps, and other entomological tools can become contaminated. The same is possible for plant surfaces where leafhoppers concentrate.

Storage of mixed insect samples in ethanol prior to sorting is a common practice. Ethanol does not dissolve or otherwise affect brochosomes, nor it washes most brochosomes off the cicadellid integuments. However, some particles come loose and either mix into solution or, possibly, float on its surface, which leads to contamination.

Another possible contamination route, which is perhaps less likely but more difficult to exclude, is through the 
ambient air, which has been shown to contain significant amounts of brochosomes [19].

Finally, perhaps the most intriguing potential route of brochosome contamination is through natural interactions between predators and parasites and their cicadellid prey or hosts, respectively. It is possible that predation may explain the presence of brochosomes on at least some of the heteropterans examined by previous authors. The bulk of species in which brochosomes have been reported belong to Miridae $[9,10]$. Most members of that family are at least facultatively zoophagous, and some are known to prey on cicadellids [20]. Even the species closely associated with particular host plants and appearing mostly herbivorous may be facultative predators. During this study S. rotermundi, closely associated with the white poplar, displayed cannibalism and sucked out small leafhopper nymphs placed into the rearing tubes. Mirids typically grasp their prey with the legs, which is consistent with the fact that in most specimens examined by previous authors $[9,10]$ brochosomes were found on the legs (which is also compatible with an aspirator or killing jar-mediated contamination scenario). Potential use of brochosomes as tracers of predaceous or parasitic interactions within natural arthropod communities is worth further study. However, such studies require exclusion of other contamination routes, while the results presented here indicate that that may be very difficult.

\section{References}

[1] G. S. Tulloch, J. E. Shapiro, and G. W. Cochran, "The occurrence of ultramicroscopic bodies with leafhoppers and mosquitoes," Bulletin of the Brooklyn Entomological Society, vol. 47, pp. 41-42, 1952.

[2] G. S. Tulloch and J. E. Shapiro, "Brochosomes," Bulletin of the Brooklyn Entomological Society, vol. 48, pp. 57-63, 1953.

[3] G. S. Tulloch and J. E. Shapiro, "Brochosomes and leafhoppers," Science, vol. 120, no. 3110, p. 232, 1954.

[4] M. F. Day and M. Briggs, "The origin and structure of brochosomes," Journal of Ultrasructure Research, vol. 2, no. 2, pp. 239-244, 1958.

[5] R. A. Rakitov, "Brochosomal coatings of the integument of leafhoppers (Hemiptera, Cicadellidae)," in Functional Surfaces in Biology, S. N. Gorb, Ed., vol. 1, pp. 113-137, Springer, Berlin, Germany, 2009.

[6] R. A. Rakitov, "On differentiation of cicadellid leg chaetotaxy (Homoptera: Auchenorrhyncha: Membracoidea)," Russian Entomological Journal, vol. 6, pp. 7-27, 1998.

[7] C. H. Dietrich, R. A. Rakitov, J. L. Holmes, and W. C. Black, "Phylogeny of the major lineages of Membracoidea (Insecta: Hemiptera: Cicadomorpha) based on 28S rDNA sequences," Molecular Phylogenetics and Evolution, vol. 18, no. 2, pp. 293 305, 2001.

[8] A. S. Frost, J. S. Gardner, and M. Nielson, "Scanning electron microscope study of brochosomes of Cercopidae," in Proceedings of the 52nd Annual Meeting of the Microscopy Society of America, pp. 358-359, August 1994.

[9] D. Wyniger, D. Burckhardt, R. Mühlethaler, and D. Mathys, "Documentation of brochosomes within Hemiptera, with emphasis on Heteroptera (Insecta)," Zoologischer Anzeiger, vol. 247, no. 4, pp. 329-341, 2008.
[10] D. Forero, "Revision of the genus Carvalhomiris (Hemiptera: Miridae: Orthotylinae)," Entomologica Americana, vol. 115, no. 2, pp. 115-142, 2009.

[11] R. A. Rakitov, "Post-moulting behaviour associated with Malpighian tubule secretions in leafhoppers and treehoppers (Auchenorrhyncha: Membracoidea)," European Journal of Entomology, vol. 93, no. 2, pp. 167-184, 1996.

[12] J. M. Cicero, J. K. Brown, P. D. Roberts, and P. A. Stansly, "The digestive system of Diaphorina citri and Bactericera cockerelli (Hemiptera: Psyllidae)," Annals of the Entomological Society of America, vol. 102, no. 4, pp. 650-665, 2009.

[13] A. T. Marshall, "Spittle production and tube-building by cercopoid nymphs (Homoptera). I. The cytology of the Malpighian tubules of spittle-bug nymphs," Quarterly Journal of Microscopical Science, vol. 105, no. 2, pp. 257-262, 1964.

[14] T. Marshall, "Spittle production and tube-building by cercopoid nymphs (Homoptera). 2. The cytology and function of the granule zone of the Malpighian tubules of tube-building nymphs," Quarterly Journal of Microscopical Science, vol. 105, no. 4, pp. 415-422, 1964.

[15] T. Marshall, "Spittle production and tube-building by cercopoid nymphs (Homoptera). III. The cytology and function of the fibril zone of the Malpighian tubules of tube-building nymphs," Quarterly Journal of Microscopical Science, vol. 106, no. 1, pp. 37-44, 1965.

[16] A. T. Marshall, "Protein synthesis and secretion by the Malpighian tubules of cercopoid larvae (Homoptera)," Journal of Insect Physiology, vol. 19, no. 12, pp. 2317-2326, 1973.

[17] A. T. Marshall, "Golgi body function and mucocomplex secretion in the Malpighian tubules of cercopoid larvae (Insecta: Homoptera)," Journal of Ultrastructure Research, vol. 47, no. 1, pp. 95-105, 1974.

[18] A. T. Marshall and W. W. K. Cheung, "Studies on water and ion transport in homopteran insects: ultrastructure and cytochemistry of the cicadoid and cercopoid Malpighian tubules and filter chamber," Tissue and Cell, vol. 6, no. 1, pp. 153-171, 1974.

[19] K. Wittmaack, "Brochosomes produced by leafhoppers-a widely unknown, yet highly abundant species of bioaerosols in ambient air," Atmospheric Environment, vol. 39, no. 6, pp. 1173-1180, 2005.

[20] A. G. Wheeler, Biology of the Plant Bugs (Hemiptera: Miridae): Pests, Predators, Opportunists, Cornell University, Ithaca, NY, USA, 2001. 

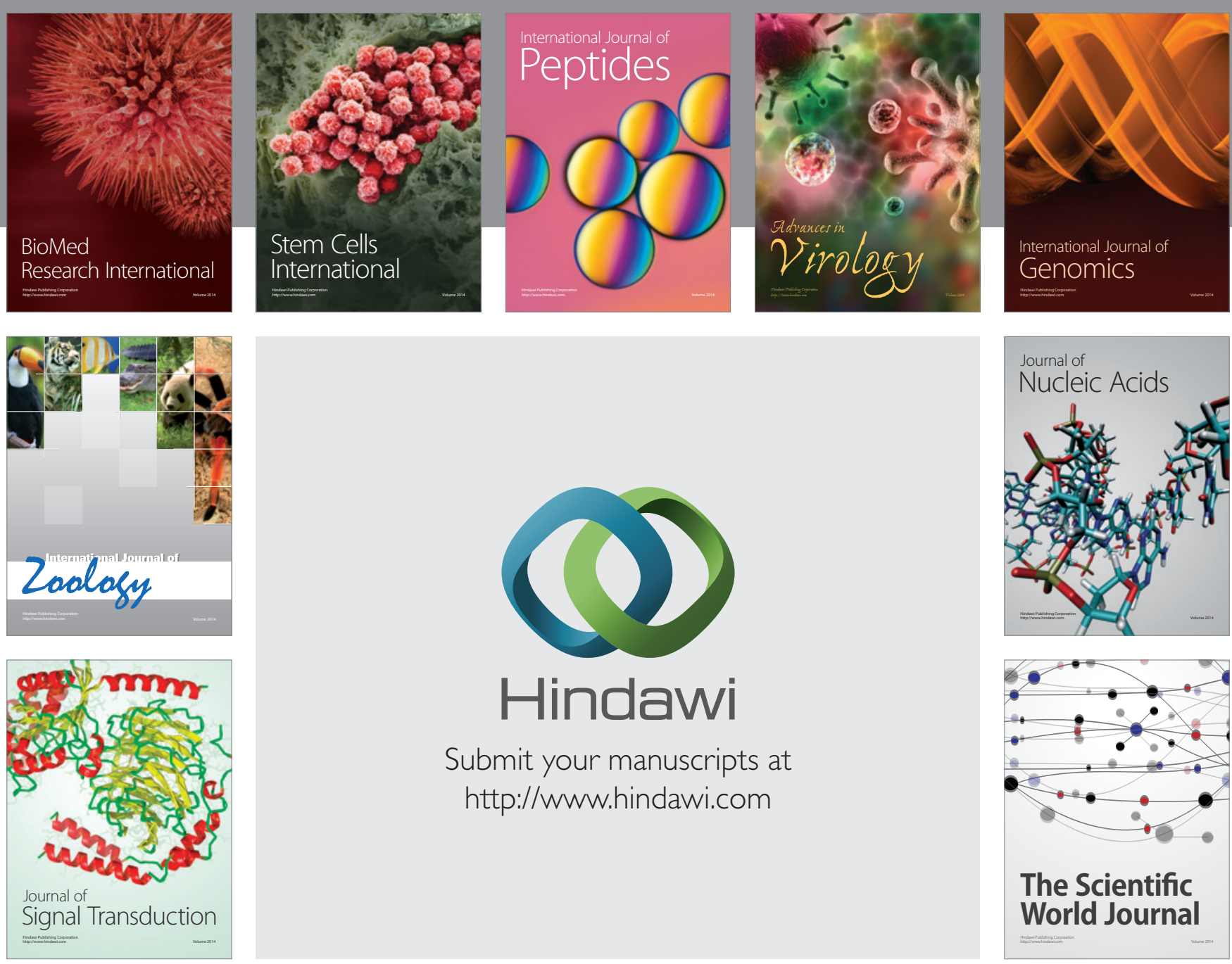

Submit your manuscripts at

http://www.hindawi.com
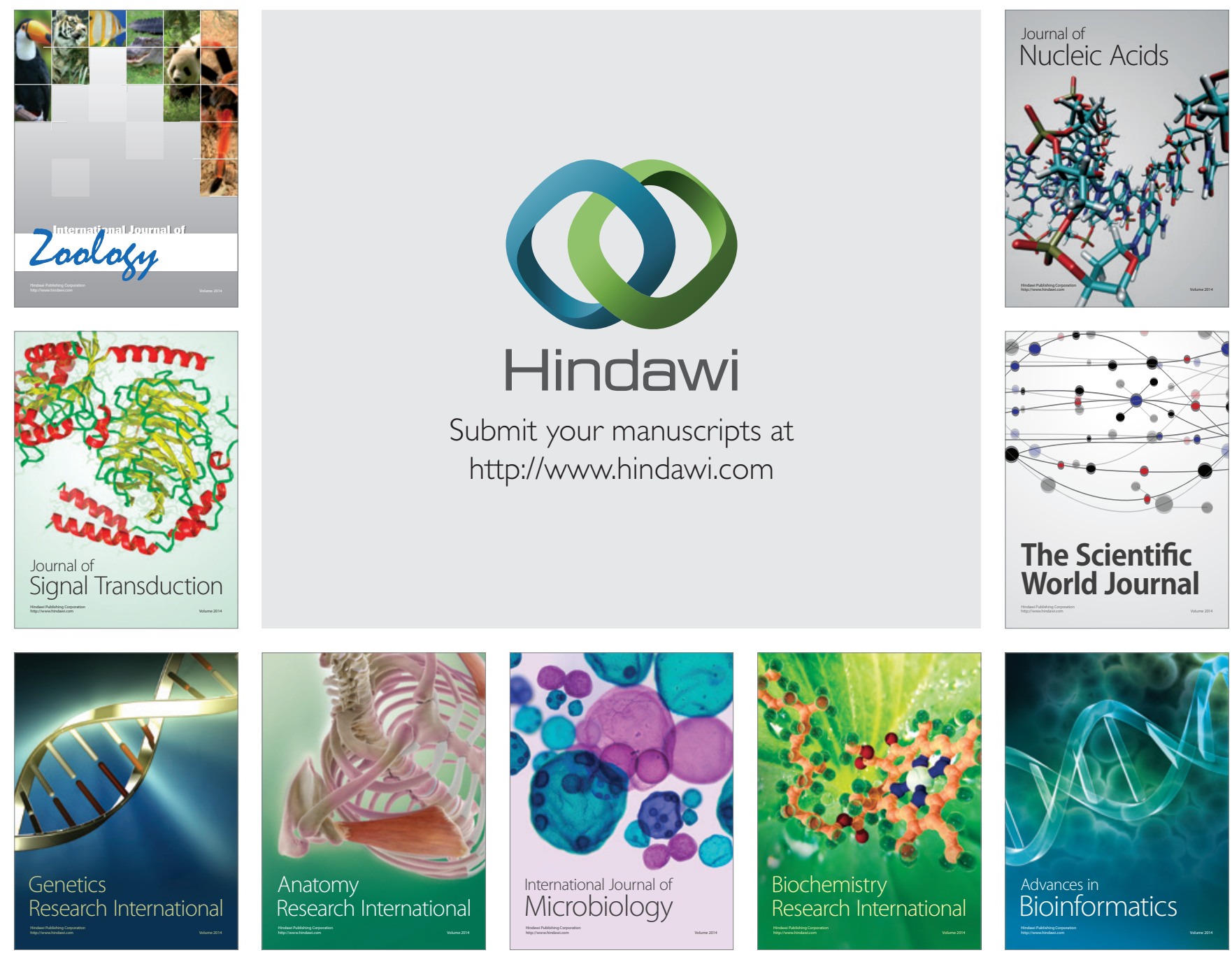

The Scientific World Journal
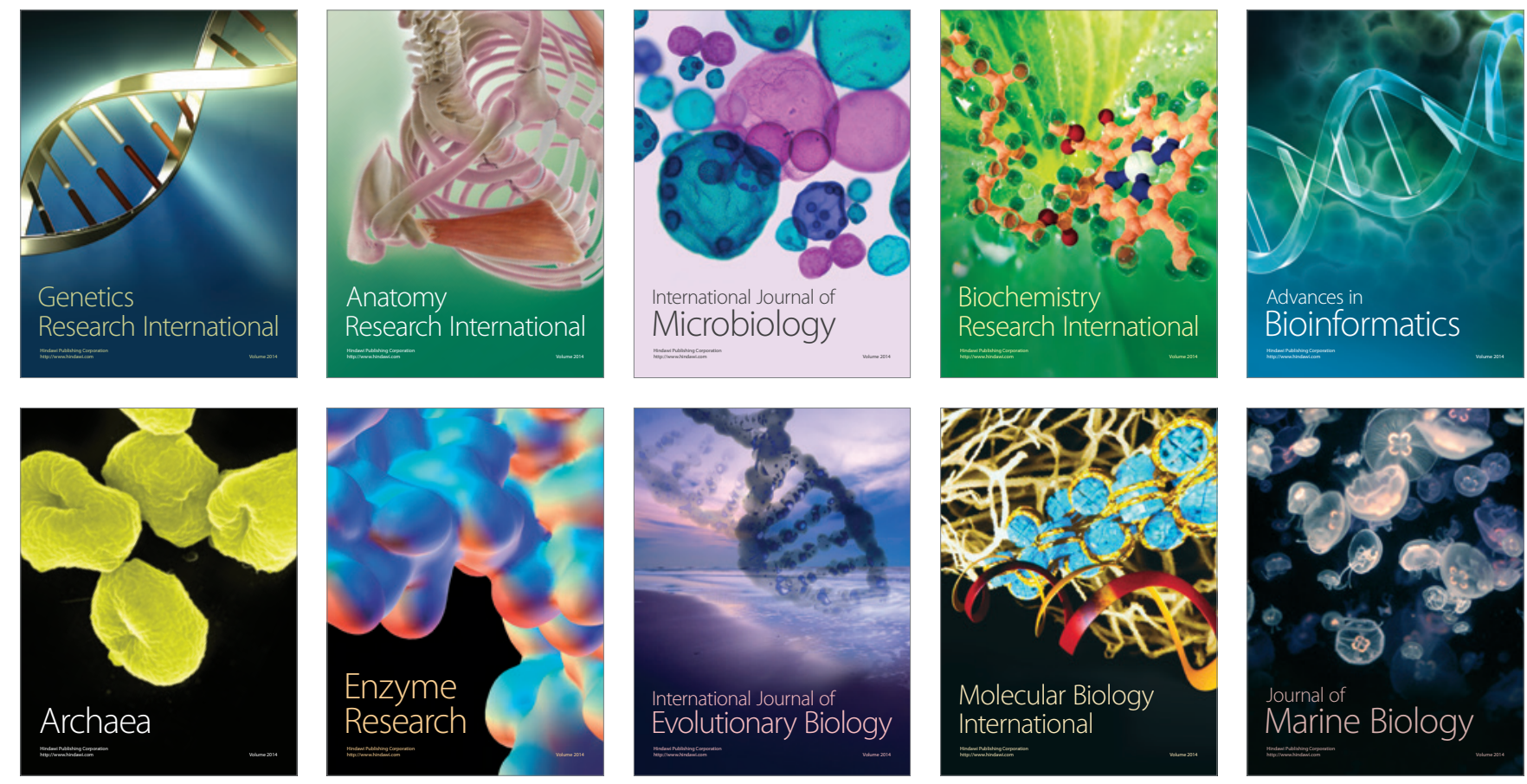